\title{
An Inducible Expression System of the Calcium-Activated Potassium Channel 4 to Study the Differential Impact on Embryonic Stem Cells
}

\author{
Stefan Liebau, ${ }^{1}$ Michael Tischendorf, ${ }^{2}$ Daniel Ansorge, ${ }^{2}$ Leonhard Linta, ${ }^{1}$ \\ Marianne Stockmann, ${ }^{1}$ Clair Weidgang, ${ }^{2}$ Michelina Iacovino, ${ }^{3}$ Tobias Boeckers, ${ }^{1}$ \\ Götz von Wichert, ${ }^{2}$ Michael Kyba, ${ }^{3}$ and Alexander Kleger ${ }^{2,4}$ \\ ${ }^{1}$ Institute for Anatomy and Cell Biology, Ulm University, 89081 Ulm, Germany \\ ${ }^{2}$ Department of Internal Medicine I, Ulm University, 89081 Ulm, Germany \\ ${ }^{3}$ Department of Pediatrics, Lillehei Heart Institute, University of Minnesota, Minneapolis, MN, USA \\ ${ }^{4}$ Institute of Molecular Medicine and Max-Planck-Research Group on Stem Cell Aging, Ulm University, \\ Albert-Einstein-Allee 11, 89081 Ulm, Germany
}

Correspondence should be addressed to Alexander Kleger, alexander.kleger@uni-ulm.de

Received 15 April 2011; Accepted 14 June 2011

Academic Editor: Gabriela Kania

Copyright () 2011 Stefan Liebau et al. This is an open access article distributed under the Creative Commons Attribution License, which permits unrestricted use, distribution, and reproduction in any medium, provided the original work is properly cited.

\begin{abstract}
Rationale. The family of calcium-activated potassium channels consists of four members with varying biological functions and conductances. Besides membrane potential modulation, SK channels have been found to be involved in cardiac pacemaker cell development from ES cells and morphological shaping of neural stem cells. Objective. Distinct SK channel subtype expression in ES cells might elucidate their precise impact during cardiac development. We chose SK channel subtype 4 as a potential candidate influencing embryonic stem cell differentiation. Methods. We generated a doxycycline inducible mouse ES cell line via targeted homologous recombination of a cassette expressing a bicistronic construct encoding SK4 and a fluorophore from the murine HPRT locus. Conclusion. We characterized the mouse ES cell line iSK4-AcGFP. The cassette is readily expressed under the control of doxycycline, and the overexpression of SK4 led to an increase in cardiac and pacemaker cell differentiation thereby serving as a unique tool to characterize the cell biological variances due to specific SK channel overexpression.
\end{abstract}

\section{Introduction}

Calcium-activated potassium channels (SKCas) of small and intermediate conductance represent a family of pore proteins which selectively transduce transmembranous potassium ion currents with differing conductance capacity [1]. Throughout the organism, these channels are expressed in tissues derived from all three germ layers, the central nervous tissue $[2,3]$, hematopoietic and muscle cells [4-6], or intestine epithelial cells [7], with distinct expression patterns. In excitable cells, SKCas are mostly involved in the generation of the hyperpolarization following the action potential [1]. Besides the modulation of the membrane potential in various tissues and cell populations, these ion channels have been found to be involved in a number of biological processes, for example, proliferation, cell differentiation, and cell morphology. As these mechanisms are present in stem or progenitor cells of different origin and potency, a role in developmental processes can be hypothesized [8-11]. Although the distinct mechanisms have not been fully understood yet, studies have shown on the one hand that the modulation of the intracellular calcium signaling by this channel family and its protein partner calmodulin might play a substantial role. On the other hand we showed in earlier studies that SKCas are important players as modulators of the cytoskeleton via specific protein-protein interaction $[9,12]$. To elucidate the developmental involvement of SK channels we utilized embryonic stem cells (ESCs) representing a bona fide model to investigate the specific role of distinct proteins during development and cell differentiation $[13,14]$. Moreover, 
SKCas have shown to be involved in the regulation of proliferation in several types of stem cells $[10,15-17]$. Recently, we were able to describe the abundance of SK channels subtypes in ESCs with SK4 being predominantly expressed. These findings were extended by our group to murine pluripotent stem cells, namely, ES and iPS cells (Liebau, unpublished data and [5]). We found in consequent experiments that increased SK channel activity resulted in a strong and fast differentiation of ES cells followed by a cell fate determination to the cardiac lineage. Precise characterization of the arising cardiomyocytes revealed the generation of a predominant population of cardiac pacemaker-like cells upon SKCa activation in both ES and iPS cells (Liebau, unpublished data and [5]). In fact, SK4 appeared to play a superior role during this process as its knockdown in embryonic stem cells led to a significantly decreased rate of cardiac differentiation [5]. Nevertheless, the impact of each particular SKCa subtype remains elusive. Apart from that, it remained unclear whether the inhibition of proliferation via SK channel activity in ES cells was solely due to a direct impact on the mitotic cell cycle or whether enhanced differentiation diminished proliferation of stem cells. This might be explained by the fact that the activation via the SKCa activator EBIO activates not only one, but all 4 subtypes, most likely having overlapping functions within the SKCa family. Unfortunately, loss of function experiments usually do not allow a stage-specific analysis and chemical inhibitors commonly harbor off-target effects. Thus, a clean and biasfree genetic system is required to dissect the contribution of each SK subtype towards the cardiac program.

Cardiac development follows a specific developmental cascade that is initiated by early mesendoderm and mesoderm formation while the heart fields arise from cells in the anterior lateral plate mesoderm of the early embryo. These fields include the precursors of both myocardial and endocardial cells, although there is apparently no common pool of bipotential precursors for these two heart cell lineages $[18,19]$. This is followed by the anlagen of a cardiogenic plate and formation of cardiac progenitor cells with varying potential to differentiate into the various cardiac subtypes. The next step is the specification of cardiomyocytes during the formation of the cardiac tissue $[20,21]$, shortly followed by expression of differentiation markers [22]. The early cardiac zone exhibits inducing activities on cardiac differentiation. This activity is not only driven by the cardiac zone but also from the anterior endoderm [19, 23-25]. Genes encoding factors of the NK homeodomain, GATA, T-box, and other families were found to exert the functions of inducive signals during specification, patterning, and differentiation of the heart [18]. Subsequently, structural and functional proteins are required during late tissue formation and the long functional period of cardiomyocytes and their respective subtypes, such as pacemaker cells of the conduction system are expressed.

The role of SK channels during this process remains to be determined as their mechanistic position within the cardiac program is still underdeveloped. Genetic engineering of ES cells, a commonly used developmental in vitro model for studying cardiac development, is often limited by several factors. This includes, for example, low or varying transfection efficiencies in transiently overexpressing constructs or, in the case of stable transfection, random insertions of the gene of interest, leading to varying insertion numbers and unforeseen side effects in the cell. Apart from that, a controllable expression of the inserted construct is highly desirable $[26,27]$. Here we report on the generation and characterization of an ESC line expressing SK4 with a doxycycline-dependent expression level and its potential impact on cardiac development from embryonic stem cells.

\section{Material and Methods}

2.1. ES Cell Culture. Embryonic stem (ES) cells were cultivated in the undifferentiated state on primary embryonic mouse fibroblasts. The mouse embryonic fibroblasts (MEFs) were inactivated by mitomycin C (Sigma-Aldrich, St. Louis, USA; final concentration $0.01 \mathrm{mg} / \mathrm{mL}$ ) incubation for $2.5 \mathrm{~h}$ $[28,29]$ before using them for ES cell culture. MEF cells were cultured in Dulbecco's modified Eagle's medium (DMEM; Invitrogen, Carlsbad, CA, USA) supplemented with $10 \%$ FCS (Invitrogen), L-glutamine (Invitrogen; final concentration $2 \mathrm{mM}$ ), nonessential amino acid mix (Invitrogen; stock solution diluted $1: 100$ ), sodium pyruvate (Invitrogen; final concentration $1 \mathrm{mM}$ ), and $\beta$-mercaptoethanol (SigmaAldrich; final concentration $\left.10^{-5} \mathrm{M}\right)$. ES cell culture was performed in Knockout DMEM (Invitrogen) supplemented with 15\% FCS (Invitrogen; stem cell tested), 1000 units $/ \mathrm{mL}$ LIF (ESGRO), and the same additions as used in the fibroblast medium [30]. ES cells were trypsinized $(0.1 \%$ Trypsin/0.02\% EDTA mixed $1: 1)$ and replated every $24-$ $36 \mathrm{~h}$ on inactivated mouse embryonic fibroblasts growing on tissue culture dishes (Nunc, Wiesbaden, Germany).

2.2. Generation of iSK4 Cells. One day before the nucleofection procedure, A2lox.cre cells were imposed to $1 \mu \mathrm{g} / \mathrm{mL}$ of doxycycline to induce Crerecombinase. ES cells were nucleofected using the Nucleofector Technology (Lonza) according to the manufacturer procedures. The Nucleofector Kit for Mouse Embryonic Stem Cells has been used upon further optimization together with program A1 and $10 \mu \mathrm{g}$ of DNA (SK4-IRES-acGFP p2lox vector) per 5 million parental A2lox.cre embryonic stem cells. Nucleofected cells were plated on neomycin-resistant, mitomycin$\mathrm{C}$-inactivated murine embryonic fibroblasts. Two days after nucleofection the assortment in ES cell medium supplemented with neomycin $(400 \mu \mathrm{g} / \mathrm{mL})$ was started. Neomycinresistant clones were picked on inactivated feeder cells and expanded for further analysis after 10 days of selection.

2.3. In Vitro Differentiation of ES Cells. In vitro differentiation of ES cells was carried out according to the standard protocol using the hanging drop method as described in $[30,31]$. Iscove's modified Dulbecco's medium (IMDM, Invitrogen) supplemented with 10\% FCS (Lonza, Basel, Switzerland), GlutaMax, NEAA, and freshly prepared monothioglycerol (Sigma-Aldrich; final concentration $450 \mu \mathrm{M}$ ) were used for differentiation. Briefly, 400 cells per $20 \mu \mathrm{L}$ differentiation 
medium were placed on the inside of lids of Petri dishes filled with $10 \mathrm{~mL}$ PBS and were cultivated for 2 days in hanging drops. After another two days of cultivation on bacteriological dishes, these 4-day-old ( $4 \mathrm{~d}$ ) embryoid bodies (EBs) $(n=20)$ were plated on $(0.2 \%)$ gelatin-coated 6 -well dishes or cover slips for RNA or immunofluorescence analysis and assayed at specific time points. RNA samples were collected 10 days after EB plating. For doxycycline (Sigma-Aldrich) treatment a $1 \mathrm{mg} / \mathrm{mL}$ stock solution was prepared in sterile water and EBs were treated at final concentration of $1 \mu \mathrm{g} / \mathrm{mL}$ doxycycline in differentiation medium from day 0 until day 10 after EB plating. Doxycycline was added to the culture medium every second day with regular medium changes. All experiments were performed at least three times. For monolayer conditions, doxycycline was added to ES cells which were kept under pluripotency conditions for three days of culture in a final concentration of $1 \mu \mathrm{g} / \mathrm{mL}$. Afterwards, cells were collected for RNA and immunostaining analysis.

2.4. Genomic PCR. Genomic ES cell DNA was isolated by the Blood \& Tissue Kit (QIAGEN, Hilden, Germany). For PCR reaction recombinant Taq DNA polymerase (Invitrogen) was used. The reaction was performed in $25 \mu \mathrm{L}$ containing $1 \mu \mathrm{L}$ DNA, $0.25 \mu \mathrm{L}$ Dream Taq/Herculase and the following final supplements: $2.5 \mu \mathrm{L}$ PCR buffer (10X), $2 \mu \mathrm{L} 1.5 \mathrm{mM} \mathrm{MgCl}_{2}$, $0.5 \mu \mathrm{L}$ of each $10 \mathrm{mM}$ dNTP, $0.3 \mu \mathrm{L}$ of each primer. PCR conditions for ES cell analysis started with denaturation at $94^{\circ} \mathrm{C}$ for $3 \mathrm{~min}$ followed by a primer-dependent number of cycles with denaturation at $94^{\circ} \mathrm{C}$ for $30 \mathrm{~s}$, annealing temperature at $61^{\circ} \mathrm{C}$ for $45 \mathrm{~s}$, and product elongation at $72^{\circ} \mathrm{C}$ for $1 \mathrm{~min}$. The following gene locus specific primer sequences have been used: LOXIN R 5' -ATA CTT TCT CGG CAG GAG CA- $3^{\prime}$, and LOXIN F $5^{\prime}$-CTA GAT CTC GAA GGA TCT GGA $\mathrm{G}-3^{\prime}$.

2.5. Quantitative One Step Real-Time PCR. One-step real time PCR was carried out according to $[9,32]$ the RotorGene Q usage instructions (QIAGEN). Amplification was monitored and analyzed by measuring the binding of the fluorescence dye SYBR Green I to the minor groove of double-stranded DNA. $1 \mu \mathrm{L}$ of total RNA was reversetranscribed and subsequently amplified using QuantiFAST SYBR Green RT-PCR Master mix (QIAGEN). QuantiTect primer assays (QIAGEN) were used in all experiments. Each RNA preparation was tested for genomic DNA contamination in a LightCycler RT-PCR by replacing reverse transcriptase with water. Tenfold dilutions of total RNA were used as an external standard curve. PCR efficiency results from the slope of these standard curves. Internal standards (house-keeping gene) and samples were simultaneously amplified. RT-PCR conditions started with $20 \mathrm{~min}$ of RT at $50^{\circ} \mathrm{C}$, followed by activation of Taq-polymerase at $95^{\circ} \mathrm{C}$ for 15 min. 45 cycles with denaturation at $94^{\circ} \mathrm{C}$ for $15 \mathrm{~s}, 58^{\circ} \mathrm{C}$ for $20 \mathrm{~s}$, and $72^{\circ} \mathrm{C}$ for $16 \mathrm{~s}$ amplified all described products with a PCR efficiency close to 3.3 (exact doubling of PCR product). To verify the specificity of the PCR amplification products, melting curve analysis was performed using the following thermal cycling profile: $95^{\circ} \mathrm{C}$ for $0 \mathrm{~s}, 65^{\circ} \mathrm{C}$ for $15 \mathrm{~s}$, and ramping to $95^{\circ} \mathrm{C}$ with stepwise signal acquisition. The concentration of each transcript was calculated by reference to the respective standard curve. Relative gene expression was expressed as a ratio of target gene concentration to housekeeping gene hydroxymethylbilane synthase (HMBS) concentration.

2.6. Immunocytochemistry. Immunofluorescence analysis was carried out as shown in $[33,34]$ with either ES cells or differentiating EBs cultivated on $0.2 \%$ gelatin-coated coverslips. The cells were rinsed in PBS and fixed with PBS containing $4 \%$ paraformaldehyde at room temperature for $20 \mathrm{~min}$. For Oct4 staining cells were incubated for $10 \mathrm{~min}$ in $0.2 \%$ Triton X (Sigma-Aldrich) followed by $30 \mathrm{~min}$ incubation in $5 \%$ goat serum in $0.5 \%$ fish skin gelatin (Sigma) to block unspecific binding. Then preparations were incubated with the primary antibody against Oct3/4 (Santa Cruz; Santa Cruz, USA; diluted $1: 400$ ) at RT in a humidified chamber for $1 \mathrm{~h}$. In case of SSEA1 staining (Developmental Hybridoma Banks, $1: 500)$ the permeabilization step was skipped. After washing three times in PBS, cells were incubated for another $1 \mathrm{~h}$ at $37^{\circ} \mathrm{C}$ with the respective Alexa fluorophore-labeled secondary antibodies. Samples were subsequently embedded in VECTASHIELD mounting medium (Vector, Burlingame USA) and analyzed by fluorescence microscopy.

2.7. Immunoblotting. iSK 4 cells were pelleted and lysed in RIPA lysis buffer ( $50 \mathrm{mM}$ tris- $\mathrm{HCl}$ pH 8.8, 1\% NP-40, $0.5 \%$ sodium deoxycholate, $0.1 \%$ SDS, $150 \mathrm{mM} \mathrm{NaCl}, 5 \mathrm{mM}$ EDTA, $10 \%$ glycerol, $2.5 \mathrm{mM} \mathrm{MgCl}_{2}$, protease, and phosphatase inhibitor cocktail) (Roche, Mannheim, Germany). After centrifugation at $14,000 \mathrm{rpm}$ for $10 \mathrm{~min}$, protein concentrations were measured in the lysates. $100 \mu \mathrm{g}$ of total protein was resuspended in Laemmli buffer and subjected to SDS-PAGE. The gels were blotted onto a PVDF membrane and blocked with 5\% milk in 0.1\% TBS-Tween buffer (TBS-T). After blocking, SK4-specific antibody was applied (1:1000 $4^{\circ} \mathrm{C}$ over night incubation) (Cell Application, San Diego, USA), beta-actin $(1: 1000)$. After washing with TBS-T samples were incubated with secondary horseradish peroxidase- (HRP-) labeled antimouse (1:4000) (Roche) or antirabbit IgG (1:5000) (Bio-Rad, Munich, Germany) antibodies in blocking solution for $1 \mathrm{~h}$ at room temperature. ECL signals were visualized and quantified using a Fujifilm LAS with the corresponding quantification software.

2.8. FACS Analysis. A single-cell suspension was generated from iSK4 using trypsin/EDTA. Finally the washed pellet was dissolved in 5\% FCS/PBS and analyzed on an LSR FACS machine (BD Bioscience, San Jose, USA) for GFP fluorescence encoded from the AcGFP cassette in iSK4 cells upon doxycycline exposure. Data were analyzed using the WinMDI software version 2.8.

2.9. Proliferation Assay. Cell proliferation assays were performed using the CellTiter-Glo Luminescent Cell Viability Assay (Promega, Madison, USA) according to the manufacturer's protocol. 

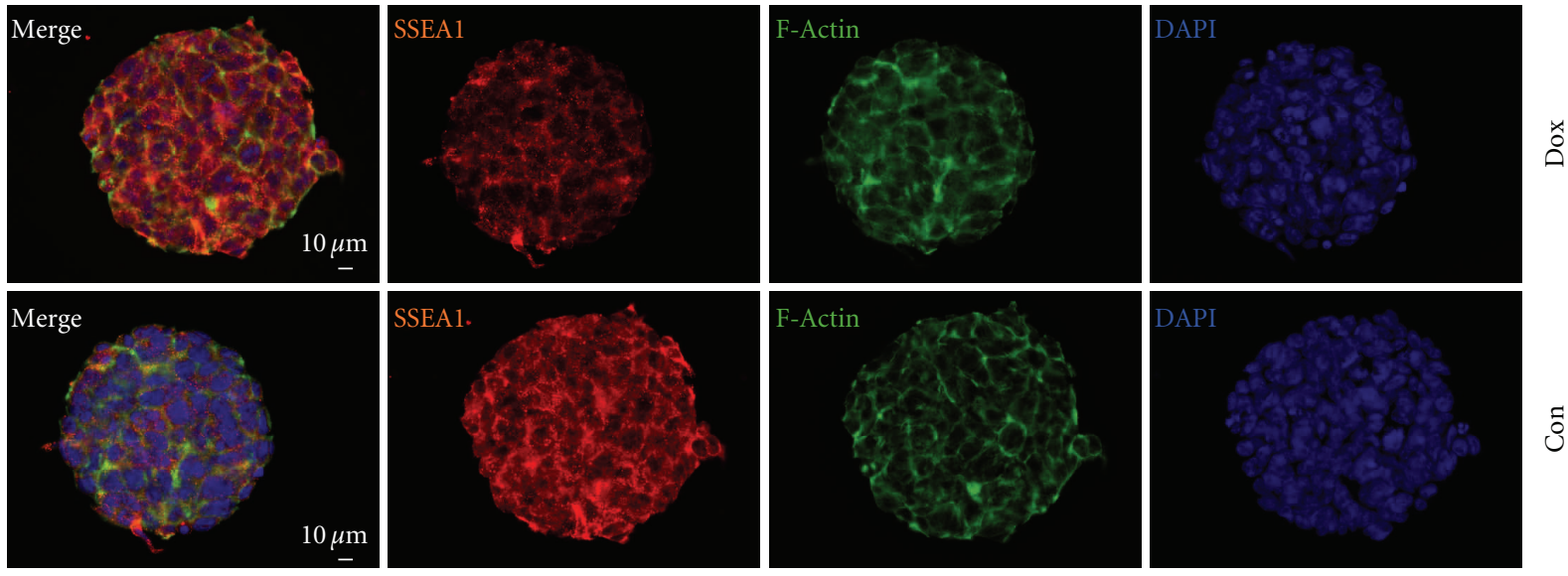

(a)
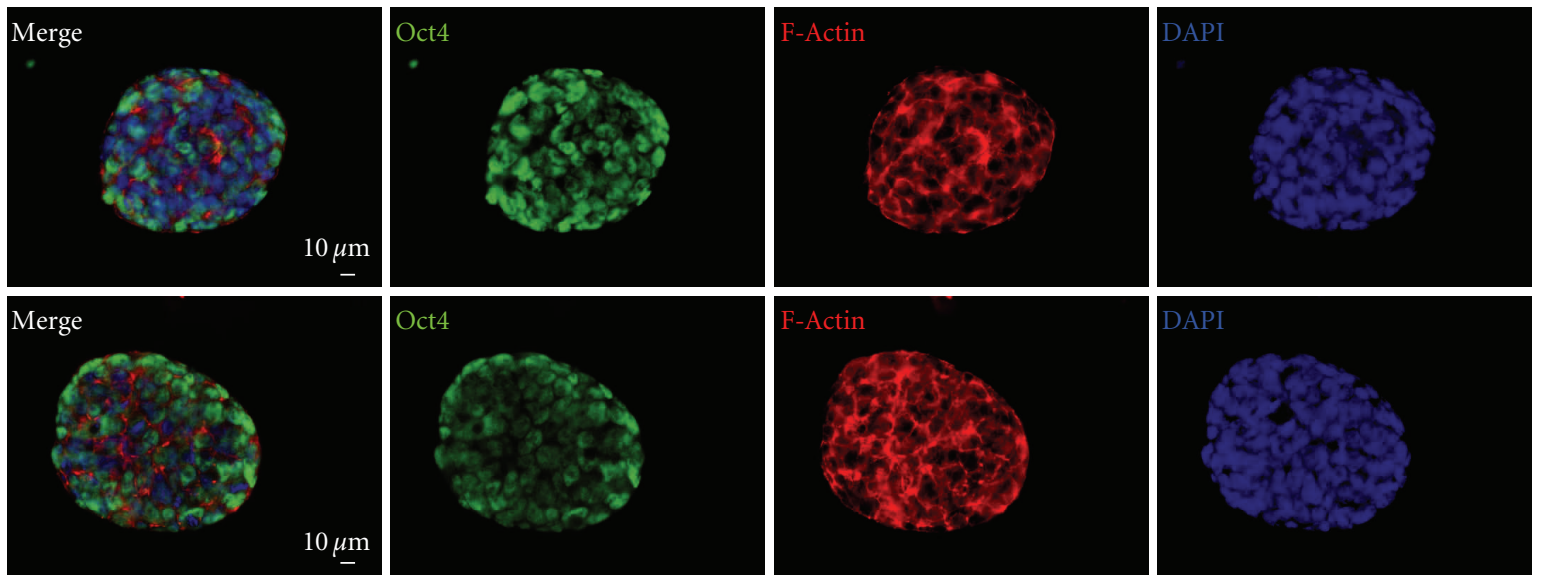

$\stackrel{\leftrightarrow}{\stackrel{\circ}{\circ}}$
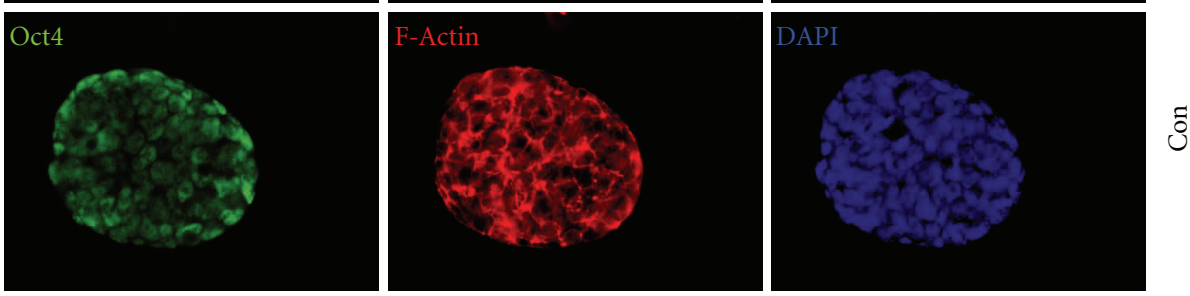

(b)

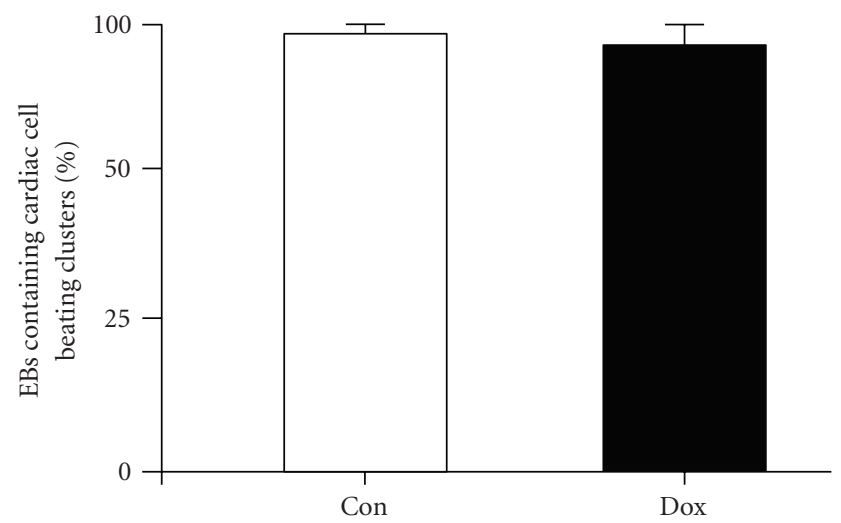

(c)

Figure 1: Effects of doxycycline treatment on A2lox.cre ES cells. (a, b) SSEA-1 (a) and Oct4 (b) staining upon 3 days of treatment with $1 \mu \mathrm{g} / \mathrm{mL}$ of doxycycline revealed no difference in expression levels. (c) EBs were plated, and the percentage of EBs containing cardiac cell beating clusters was determined in dox-treated versus untreated cultures on day 10 after EB plating on day 4.

\section{Results}

3.1. Generation of SK4-AcGFP Inducible Knock in ES Cell Lines (iSK4). First, we assessed whether a doxycycline inducible system fits our requirements of being neutral with respect to differentiation of embryonic stem cells. To this end, we used wild-type ES cells and treated them with the respected concentration of doxycycline for three days. We could not observe any differences neither on the expression of common pluripotency markers such as SSEA1 or Oct4 (Figures 1(a) and $1(\mathrm{~b})$ ) nor on the numbers of cardiac beating clusters (Figure $1(\mathrm{c}))$. Next, we started out with the construction of 

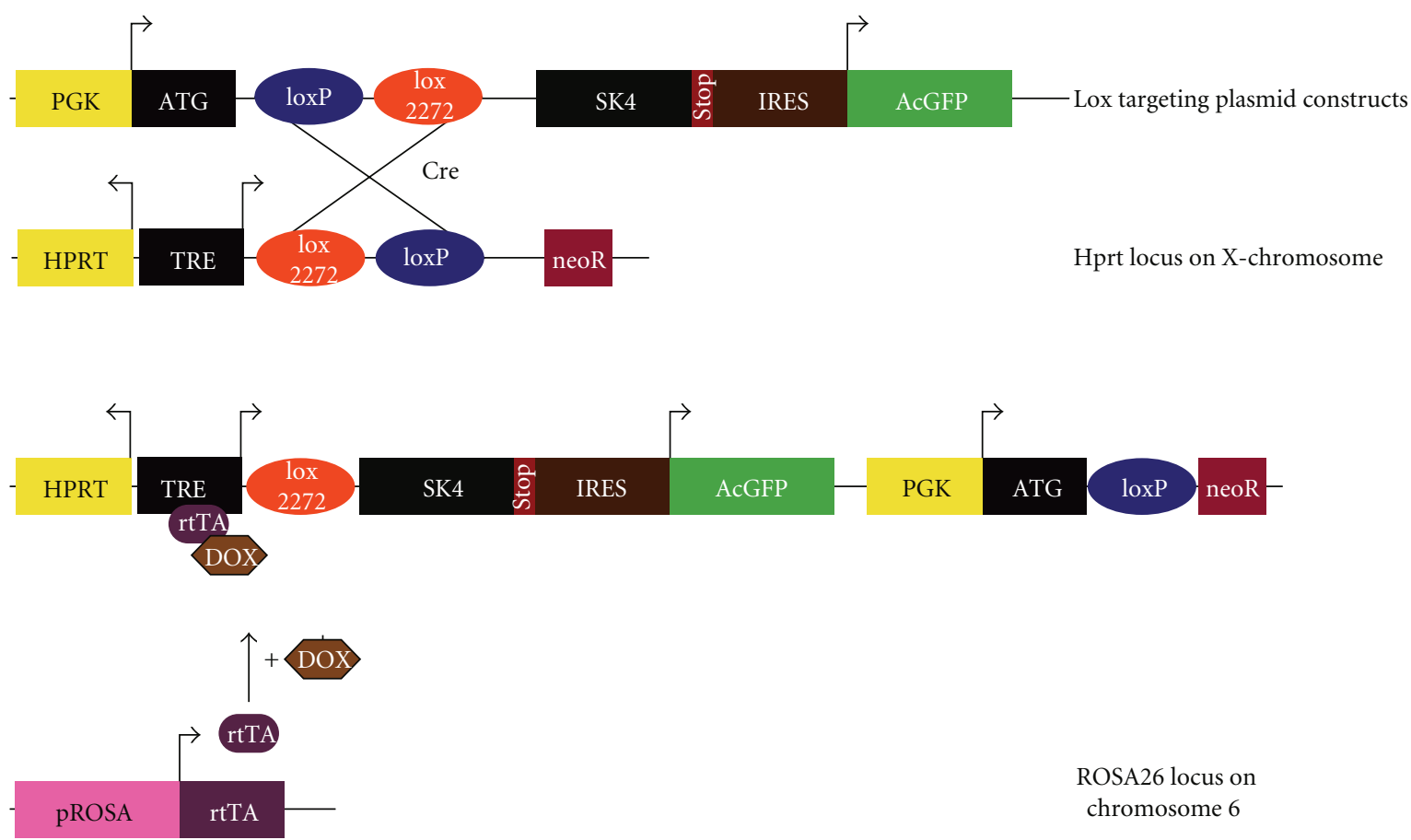

ROSA26 locus on chromosome 6

(a)

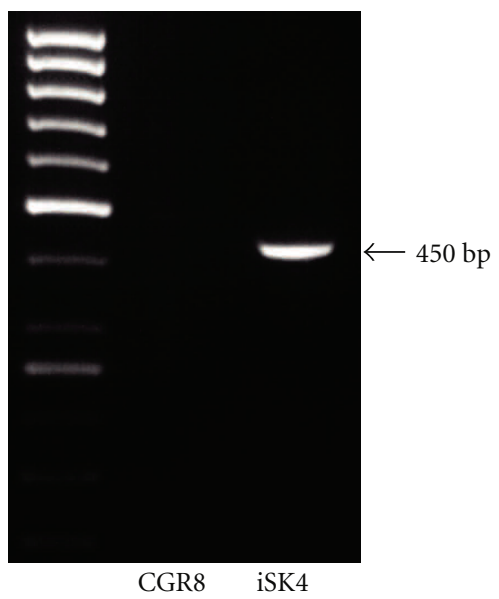

(b)

Figure 2: Construction of the iSK4 cell line. (a) Scheme of the expression cassette integrated into the desired loci. The ES cell line A2lox.cre harbors an rtTA in the constitutive ROSA26 locus on chromosome 6. A neomycin (noeR) resistance is recombined upon integration of the targeting vector. Recombination of the construct into the prepared site on the X-chromosome is facilitated by Cre. Transgenic cells can subsequently be selected by G418 (neo). tetOP: tetracycline response element; PGK: phosphoglycero kinase promoter; ATG: methionine initiation codon; black triangle: lox recognition sequence for Cre recombinase; GFP: green fluorescent protein; Neo: truncated neomycin (G418) resistance gene; pA: polyadenylation sequence. (b) Lox-in PCR verifies the correct integration of the expression cassette at determined loci on chr6 by amplifying a product at the size of $\sim 450 \mathrm{bp}$. Untargeted ES cells were used as a control.

the desired SK4 expressing plasmid. The SK4 construct (a kind gift of Dr. Begenisich) was originally cloned into the pcDNA3.1 vector [35]. The construct was amplified by PCR introducing the required restriction sites to the sequence and was subsequently ligated into the pIRES2-AcGFP vector. In this vector, the green fluorophore is encoded by the same RNA that harbors the channel protein code but separated by an internal ribosome entry sequence (IRES) leading to the translation of a GFP which is not fused to the gene of interest. This was desirable as fluorophores are large proteins of approximately $30 \mathrm{kD}$ and, fused to other proteins, may cause misfolding, wrong localization, or impaired function of the protein of interest [36]. This vector harbors the green fluorophore found in the jellyfish Aequorea coerulescens (Ac). For the controlled and defined expression of the constructs in ES cells we utilized a genetically modified ES cell line 

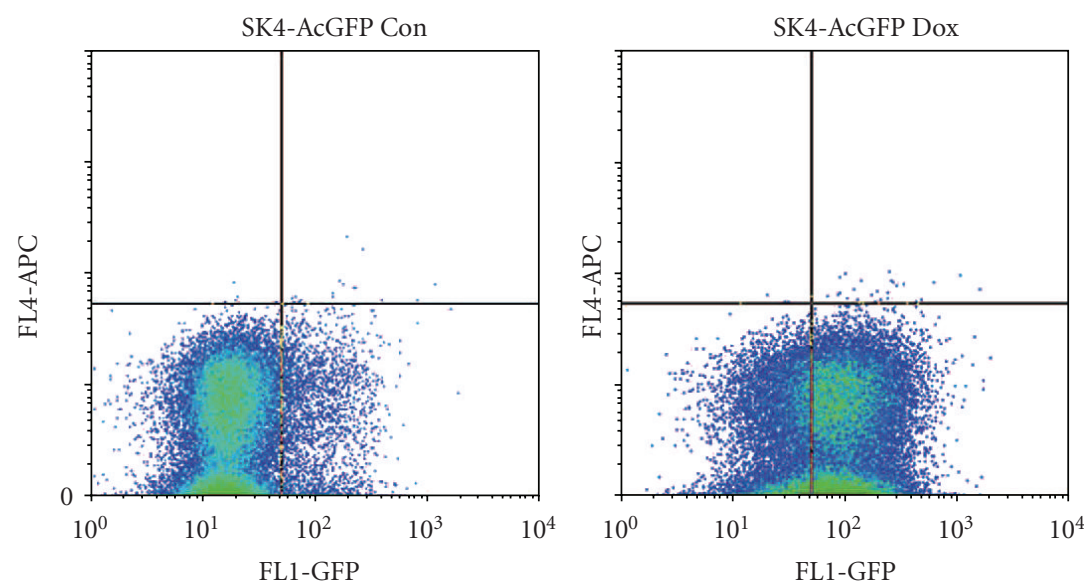

(a)
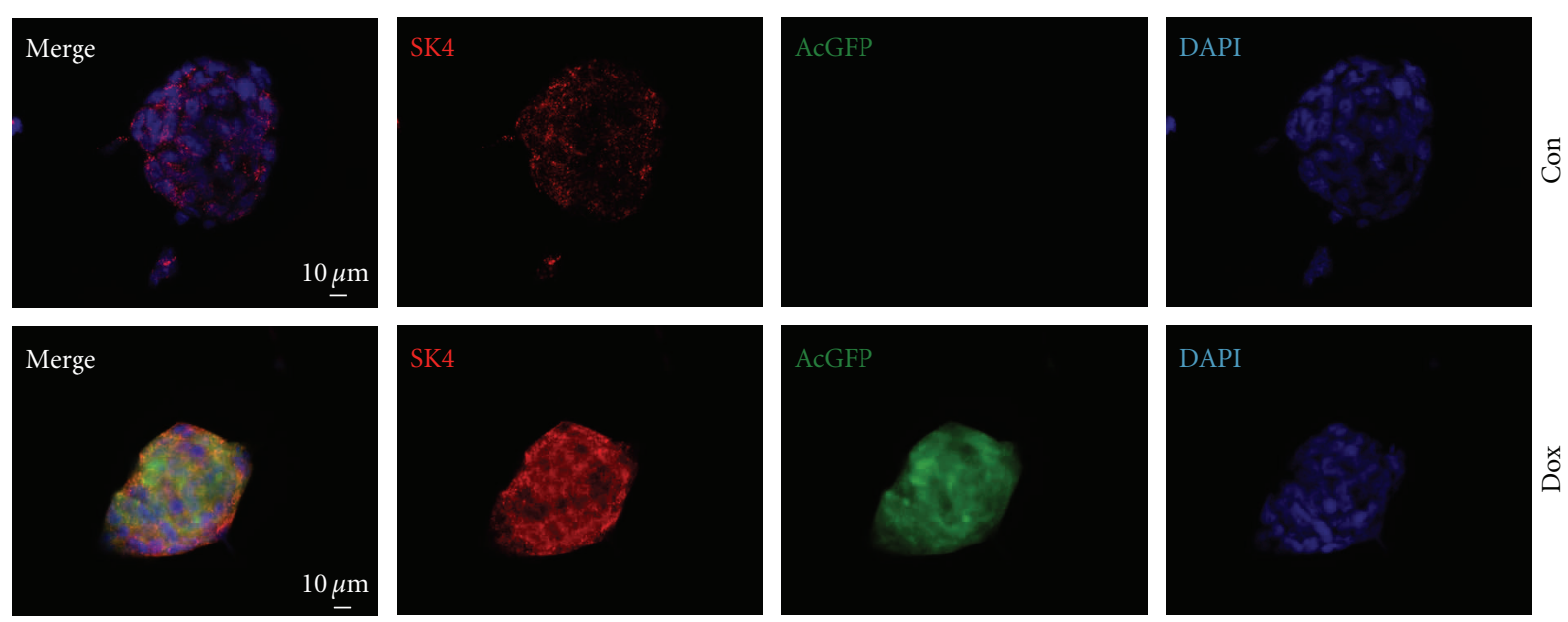

(b)

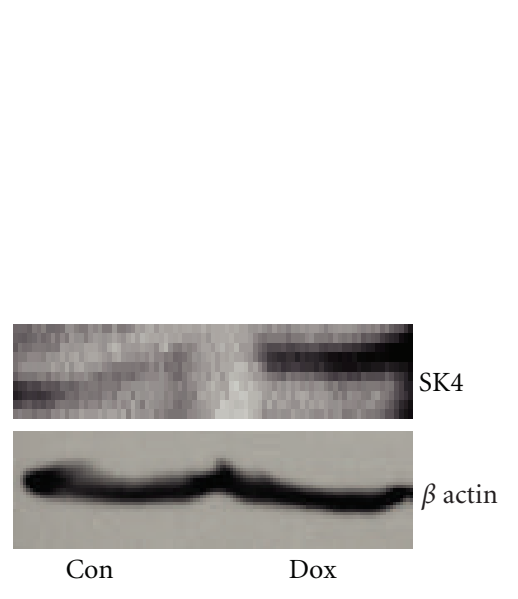

(c)

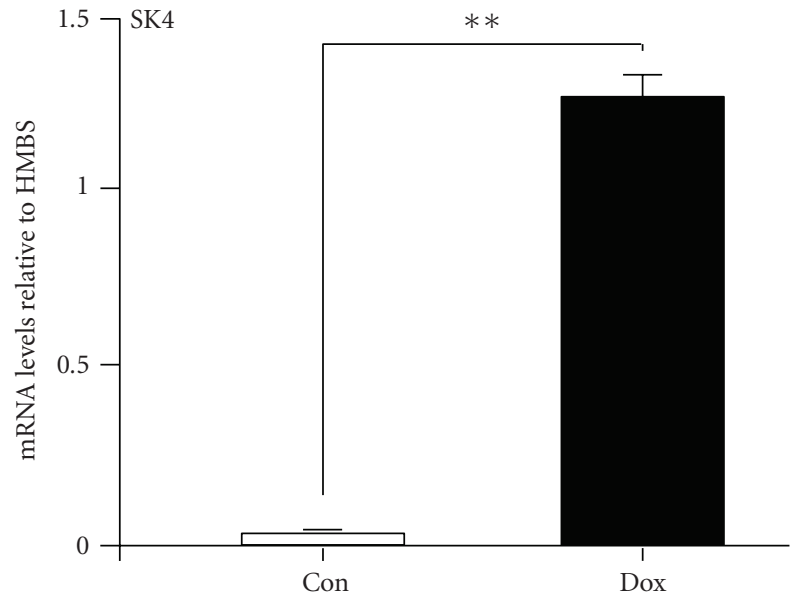

(d)

FIgURE 3: Characterization of iSK4 cells. (a) Flow cytometry by FACS shows a major proportion of the doxycycline-treated cells to exhibit green fluorescence $(>75 \%)$. (b, c) Neomycin-selected iSK4 clonal cultures show dox-dependent elevation of SK4 proteins. (b) Iimmunocytochemistry using specific SK4 antibodies shows highly elevated protein levels of SK4 in the colonies after 1 day of doxycycline treatment. Dox-treated cells exhibit the AcGFP fluorescence (green) in contrast to controls. Both treated and untreated cells express SK4 proteins (red) with a strong increase in the dox-treated cells. Elevated SK4 proteins upon dox treatment was underlined by (c) by immunoblot. Nuclei are stained by DAPI (blue). Scale bars as indicated. (d) SK4 transcript increase upon doxycycline treatment is validated by real-time one-step RT-PCR. 

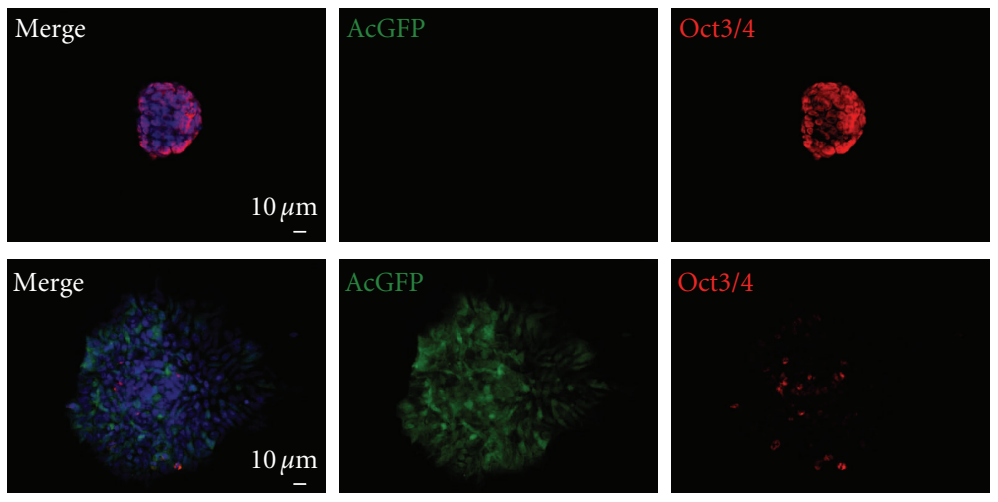

(a)
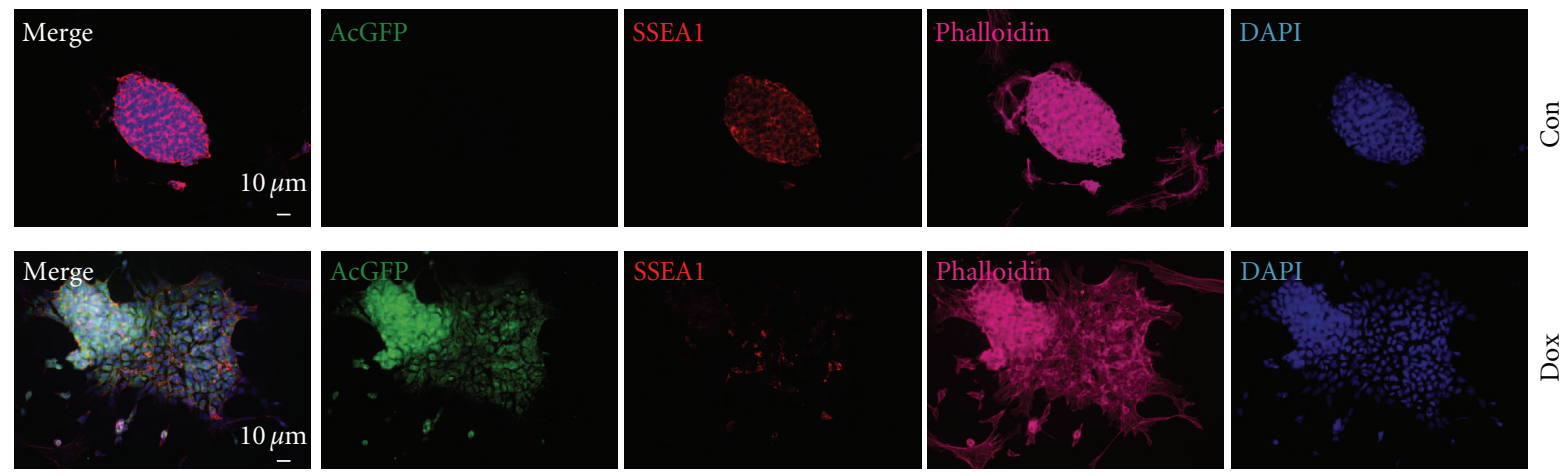

(b)

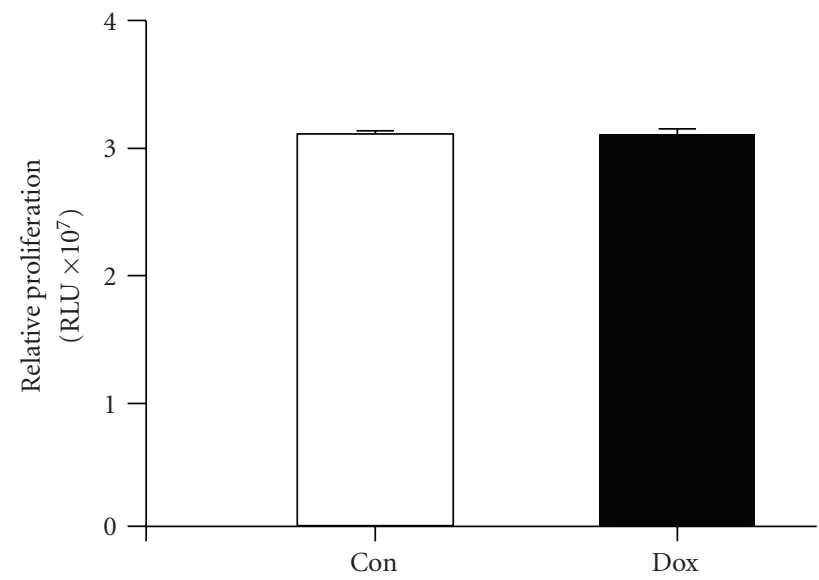

(c)

Figure 4: Doxycycline treatment alters cell behavior. (a) Elongated dox treatment for 3 days alters the pluripotency and morphology of the ES cells. Oct3/4 proteins (red) are decreased, and green fluorescence is solely expressed by dox-treated cells. (b) In line, the ES cell marker SSEA1 is lost during dox treatment (red), and the actin cytoskeleton, visualized by the f-actin marker phalloidin, is altered upon dox treatment. (c) Proliferation of iSK4 cells is not changed by dox-treatment shown in a proliferation assay. $(n=4)$ for all experiments. Nuclei are stained by DAPI (blue). Scale bars as indicated.

and the corresponding vector system initially generated by Iacovino et al. (submitted). The murine ES cell line (called A2lox.cre) allows the targeting of the requested transgene to an X-chromosomal locus, upstream of HPRT, in a controllable manner, as the pROSA26 locus already harbors a reverse tetracycline transactivator. The Crerecombinase encoding cDNA has been inserted into the HPRT locus in between lox $\mathrm{P}$ and lox $\mathrm{M}$ within A2lox.cre cells and is self-excised [37].
The cre-cassette is exchanged for the plasmid of interest (here SK4-pIRES AcGFP), upon induction of the cre protein by doxycycline (Figure 2(a)). This system has been shown to be suitable to dissect the impact of certain factors on cardiac differentiation in ES cells $[38,39]$. For SK4, the complete cassette consisting of the SK4 coding sequence, the pIRES site, and the GFP was excised by restriction enzymes suitable for the p2lox system. Doxycycline inducible SK4 ES cells 


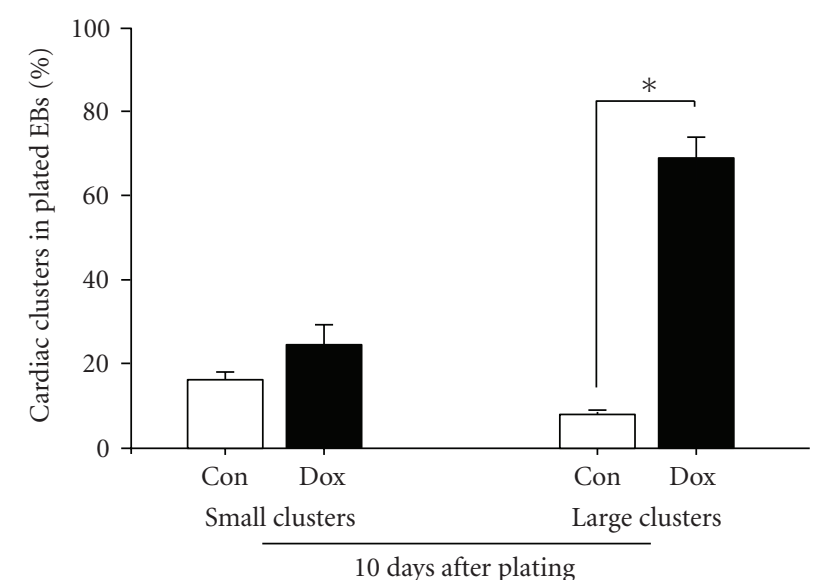

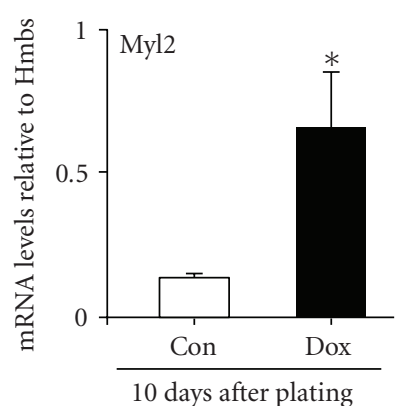

(b)

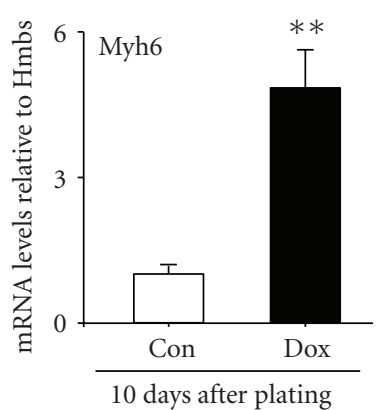

(c)

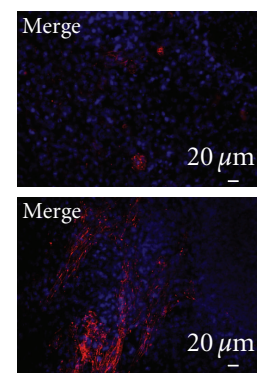

(a)

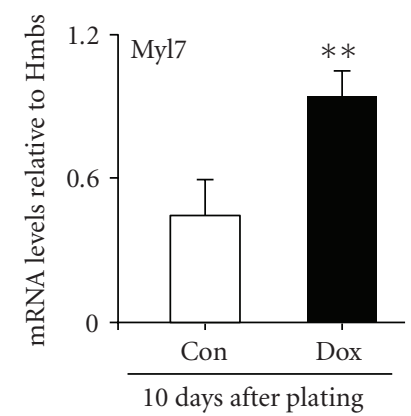

(d)

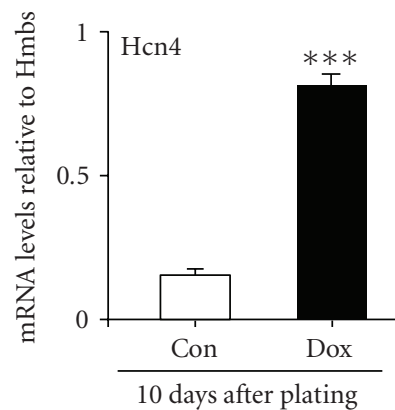

(e)
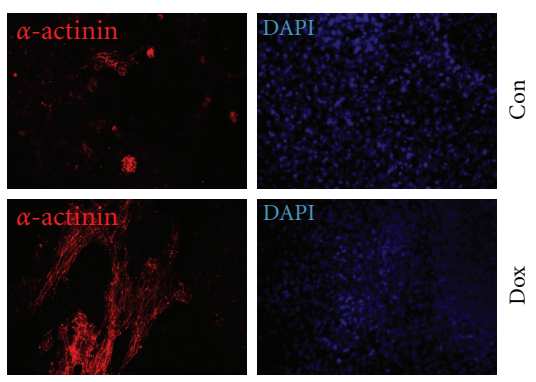

(f)

Figure 5: Cardiac differentiation is increased upon doxycycline treatment. (a) The number and size of cardiac clusters arising in dox-treated and untreated cultures were evaluated and counted. Dox treatment leads to a strong increase in both number and size of spontaneously beating cell clusters 10 days after plating. Small clusters: $<100 \mu \mathrm{M}$; big clusters $>100 \mu \mathrm{M}$. (b-e) Expression of cardiac marker genes upon induction of SK4. On mRNA level, the cardiac specific transcripts Myh2 (b), Myh6 (c), Myl7 (d), and Hcn4 (e) are significantly elevated upon dox treatment $(n=4)$. (f) This is also evident in immunocytochemical stainings using cardiac specific antibodies directed against $\alpha$ actinin (red). The size of cardiac clusters is highly increased 10 days after plating. Nuclei are stained by DAPI (blue). Scale bars as indicated.

were generated by subcloning the SK4 cDNA into p2Lox [40] and using the derivative p2Lox-SK4 to target the inducible locus of A2Lox.cre ES cell (Iacovino et al., submitted). This cell line is an improved version of A2Lox [40] in which a floxed cre-cassette has been engineered downstream of a doxycycline inducible promoter upstream of HPRT on the X chromosome. A2Lox.cre cells were treated with $500 \mathrm{ng} / \mathrm{mL}$ doxycycline for 24 hours and harvested by trypsinization. Cre expression catalyzed replacement of the cre-cassette by the incoming SK4 cassette from p2Lox-SK4. Summarized, we chose a doxycycline controlled expression system which on the one hand harbors a cassette generating an untagged full length channel protein. On the other hand this system allowed us to select stable transfected ES cells by either FACS sorting for the soluble green fluorescing protein or via the ES cell-line-specific neomycin resistance that is solely expressed in the case of successful transfection. First, we transfected A2lox.cre cells with the according construct. Subsequently, neomycin-resistant clones were manually picked and subcultured for further analysis. Next, we checked whether the inducible cassette exchange was successful via analyzing the genomic locus. The band at $450 \mathrm{bp}$ marks the successful targeting event in the cell line while no band was visible in nontransgenic CGR8 ES cells (Figure 2(b)). 
3.2. Characterization of iSK4 ES Cells. In a primary approach we sought to verify the appropriate features of the transgenic cells. Therefore, we tested the desired expression of the green fluorophore in a doxycycline-dependent manner. In comparison to the untreated cultures FACS analysis of doxycyclinetreated iSK4 cells showed a robust expression of the AcGFP regarding most of the subcultured clones (Figure 3(a)). Secondly, as expected, the induction of the transgene upon application of doxycycline treatment was detectable on protein levels and mRNA. Protein levels upon dox treatment were investigated either by immunofluorescence or by immunoblotting. We could detect both the endogenous expression of the channel protein and a specific increase of the expected transgenic channel proteins (Figures 3(b)$3(\mathrm{c}))$. This was further underlined by the detection of both the endogenous and overexpressed channel transcripts at doxycycline-dependent quantities (Figure 3(d)), investigated by qPCR. Further experiments were performed with several clones expressing comparable levels of SK4 under doxycycline (not shown).

3.3. Role of SK4 Overexpression in iSK4 Cell Lines. Although we observed in earlier studies that SK4 activity is crucially involved in ES cell differentiation and subsequent generation of cardiac and cardiac pacemaker-like cells, we did not yet know what impact the simple overexpression of this channel would have on the generated iSK4 ES cell line under several conditions. This is of particular interest as expression does not necessarily mean activity in case of ion channels. In fact, this would point to signaling events which are not directly linked to the membrane potential itself, as we previously reported for neural stem cells [12]. In a first step we looked for both initiation of differentiation and changes of the cell cycle upon doxycycline supplementation. In immunocytochemical stainings we observed a clear change of ES cell colony morphology and loss of pluripotency markers in iSK4 cells upon doxycycline-induced expression of SK4. This was true for the common markers Oct $3 / 4$ and SSEA1, respectively. The GFP protein seen in the green channel marks the transgene expression of the SK4 protein during this assay (Figures 4(a)-4(b)). ES cells are characterized by a unique cell cycle regulation which comprises fast selfrenewing of this cell system and differentiation is usually accompanied by changes in the proliferation rates in ES cells. Nevertheless, cell titer glow assays did not show a change in proliferation capacity upon SK4 overexpression (Figure 4(c)).

3.4. Cardiac Differentiation Capacity of iSK4 ES Cells. SK channel activity strongly drives the cell fate of differentiating ES cells towards the cardiac lineage. In particular this was the case upon embryoid body-induced germ layer formation and subsequent increased SK channel activity after EB plating. Different doxycycline-treatment regimens were applied during differentiation, and cultures were analyzed regarding their cardiac differentiation potential, according to morphological criteria at several time points (data not shown). In the end, we discovered that continuous doxycycline treatment during differentiation had the strongest cardiac inducing effect. Obviously, increased SK4 expression led to highly elevated numbers of cardiac clusters with an additional increase in the size of the beating areas as shown by the high abundance of small clusters and a significant switch to form large clusters in comparison to control cells (Figure 5(a)). Next, we wanted to know whether this cardiac inducing effect is further mirrored by increased cardiac gene expression levels. A strong upregulation of the general cardiac marker gene Myl2 (4.6 fold; Figure 5(b)) was observed upon SK4 expression. Also atrial-specific genes such as Myh6 [41, 42] (5.6 fold) and Myl2a (2.07 fold) were strongly up-regulated (Figures 5(c) and 5(d)). This suggested us to investigate the expression levels of $\mathrm{HCN} 4$, belonging to the family of channels responsible for the hyperpolarization activated current, $I_{f}$. HCN4 plays a major role in the pacemaker potential of the sinoatrial node (SAN). It labels pacemaker tissues including the SAN, serves as an excellent nodal marker, and was strongly up-regulated upon SK4 induction (5.48 fold, Figure 5(e)). This was further underlined by the immunocytochemical detection of large $\alpha$-actinin-positive clusters in the dox-treated cultures compared with only a few positive cells under control conditions (Figure 5(f)).

\section{Discussion}

Here we report the successful generation and characterization of a murine embryonic stem cell line overexpressing the subtype 4 of calcium-activated potassium channels in a doxycycline dependent manner. These cells were investigated concerning their impact of SK4 on cardiac differentiation derived from ES cells.

In an earlier study we were able to show that murine EScells change their cell fate determination in an SK activity dependent manner. Increased SK activity led to the differentiation of ES cells into a high proportion of cardiomyocytes with the majority of the cells showing functional and morphological properties of cardiac pacemaker cells. These experiments were mainly based on the potentiation of SK channel activity mediated by the commonly used chemical compound 1-EBIO (1-ethyl-2-benzimidazolinone). Mechanistically, the EBIO-induced increase in $\mathrm{Ca}^{2+}$-sensitivity is suggested to result from the interaction of the benzimidazolinone with the $\mathrm{Ca}^{2+}$ gating apparatus of SK channels [43]. EBIO is known to nonselectively activate all SK subtypes [44] which makes it difficult to dissect the distinct biological role of the individual SK channel subtypes. In addition, the functional potassium gating pore is composed of four subunits which can consist of either 4 similar SK channel proteins (homomeric) or can be a mix of several different SK subunits (heteromeric) in vitro, leading to functional alterations [45], and in vivo [46, 47]. Furthermore, all SK channel subtypes display a variety of splice variants with yet unclear functional diversity [47-50]. In our primary studies we tried to dissect cardiac inducing effects upon SKCa activity by applying different kinds of inhibitors. However, these experiments were partly biased by cytotoxicity of the inhibitors. Therefore, we generated SK4 knockdown cells which showed 
that depletion of SK4 "rescues" this inductive effect by strongly diminishing cardiac differentiation in these cultures [5]. Still, the mechanistic role of SK4 channel remained unclear. This led us to the idea of systematically exploring the exact role of this subtype during ES cell differentiation by applying a clean and straightforward genetic system allowing stage-specific expression of SK4 in ES cells. Several gain of function systems, for example, lentiviral transduction or transfection followed by selection for stable clones were considered for these approach. However, none of this approaches fulfilled all the respective criteria in one system, namely, (i) inducible and (ii) dose-dependent expression of the inserted cDNA (iii) from a defined genetic locus (iv) without random insertion-based bias of data interpretation [37]. These requirements led us to use A2lox.cre cells due to the following superior characteristics. First of all, this system allows a simple cloning of the gene of interest in a stable plasmid vector which comprises easy-to-use restriction sites for ligation. Secondly, the targeting strategy to a specific locus circvents insertion-based gene dysfunction. Together with the doxycycline inducible transcript expression of SK4 all mentioned problems were solved and allowed us to study the cell biological and developmental role of this SK channel subtype in ES cells. We found a decrease of pluripotency marker proteins upon overexpression for several days. Still, in contrast to direct increased SK channel activity by 1-EBIO in nontransgenic ES cells, we could not observe a change in proliferation rates under SK4 overexpressing conditions in iSK4 cells. Several reasons might be responsible for that finding, for example, the influence of other SK channel subtypes, heteromeric channel composition or ES-cell-specific splice variants. As for the next step, we investigated several regimens of stage-specific overexpression of SK4, starting with doxycycline treatment during distinct phases of cardiac in vitro differentiation (day 0-2: mesendoderm formation; day 2-4: mesoderm formation; day 4-9: formation of cardiac progenitors). We found that concerning cardiac differentiation, continuous transgene activation was successfully inducing cardiac myocyte generation. We could proof that by increased mRNA levels for cardiac transcripts and on protein levels. This clearly underlined the specific role of SK4 channel proteins during ES cell differentiation towards a cardiac cell fate. The ability to modulate expression times, expression in various cell stages and in a quantitative manner finally gives us the possibility to study these channel proteins under further conditions. Furthermore, it comprises the possibility to investigate participating signals which support or mediate SK channel-induced mechanisms. Solely under circumstances which combine understatement of SK channel behavior with their influence on cellular mechanisms we might be able to translate SK channel-mediated stem cell differentiation into the human system.

\section{Authors' Contribution}

S. Liebau and M. Tischendorf contributed equally to the paper.

\section{References}

[1] M. Stocker, " $\mathrm{Ca}^{2+}$-activated $\mathrm{K}^{+}$channels: molecular determinants and function of the SK family," Nature Reviews Neuroscience, vol. 5, no. 10, pp. 758-770, 2004.

[2] M. Stocker and P. Pedarzani, "Differential distribution of three $\mathrm{Ca}^{2+}$-activated $\mathrm{K}^{+}$channel subunits, SK1, SK2, and SK3, in the adult rat central nervous system," Molecular and Cellular Neurosciences, vol. 15, no. 5, pp. 476-493, 2000.

[3] M. K. Boettger, S. Till, M. X. Chen et al., "Calcium-activated potassium channel SK1- and IK1-like immunoreactivity in injured human sensory neurones and its regulation by neurotrophic factors," Brain, vol. 125, no. 2, pp. 252-263, 2002.

[4] S. Ohya, S. Kimura, M. Kitsukawa, K. Muraki, M. Watanabe, and Y. Imaizumi, "SK4 encodes intermediate conductance $\mathrm{Ca}^{2+}$-activated $\mathrm{K}^{+}$channels in mouse urinary bladder smooth muscle cells," Japanese Journal of Pharmacology, vol. 84, no. 1, pp. 97-100, 2000.

[5] A. Kleger, T. Seufferlein, D. Malan et al., "Modulation of calcium-activated potassium channels induces cardiogenesis of pluripotent stem cells and enrichment of pacemaker-like cells," Circulation, vol. 122, no. 18, pp. 1823-1836, 2010.

[6] J. F. Hoffman, W. Joiner, K. Nehrke, O. Potapova, K. Foye, and A. Wickrema, "The hSK4 (KCNN4) isoform is the $\mathrm{Ca}^{2+}$ activated $\mathrm{K}^{+}$channel (Gardos channel) in human red blood cells," Proceedings of the National Academy of Sciences of the United States of America, vol. 100, no. 12, pp. 7366-7371, 2003.

[7] L. A. Simms, J. D. Doecke, R. L. Roberts et al., "KCNN4 gene variant is associated with ileal crohn's disease in the Australian and New Zealand population," American Journal of Gastroenterology, vol. 105, no. 10, pp. 2209-2217, 2010.

[8] H. Jäger, T. Dreker, A. Buck, K. Giehl, T. Gress, and S. Grissmer, "Blockage of intermediate-conductance $\mathrm{Ca}^{2+}$-activated $\mathrm{K}^{+}$channels Inhibit human pancreatic cancer cell growth in vitro," Molecular Pharmacology, vol. 65, no. 3, pp. 630-638, 2004.

[9] S. Liebau, B. Vaida, C. Proepper et al., "Formation of cellular projections in neural progenitor cells depends on SK3 channel activity," Journal of Neurochemistry, vol. 101, no. 5, pp. 13381350, 2007.

[10] S. P. Wang, J. A. Wang, R. H. Luo, W. Y. Cui, and H. Wang, "Potassium channel currents in rat mesenchymal stem cells and their possible roles in cell proliferation," Clinical and Experimental Pharmacology and Physiology, vol. 35, no. 9, pp. 1077-1084, 2008.

[11] D. L. Tharp, B. R. Wamhoff, J. R. Turk, and D. K. Bowles, "Upregulation of intermediate-conductance $\mathrm{Ca}^{2+}$-activated $\mathrm{K}^{+}$channel (IKCa1) mediates phenotypic modulation of coronary smooth muscle," American Journal of Physiology, vol. 291, no. 5, pp. H2493-H2503, 2006.

[12] S. Liebau, J. Steinestel, L. Linta et al., "An SK 3 channel/nWASP/ Abi-1 complex is involved in early neurogenesis," PLoS ONE, vol. 6, no. 3, p. e18148, 2011.

[13] S. Irion, M. C. Nostro, S. J. Kattman, and G. M. Keller, "Directed differentiation of pluripotent stem cells: from developmental biology to therapeutic applications," Cold Spring Harbor Symposia on Quantitative Biology, vol. 73, pp. 101-110, 2008.

[14] S. J. Kattman, E. D. ler, and G. M. Keller, "Specification of multipotential cardiovascular progenitor cells during embryonic stem cell differentiation and embryonic development," Trends in Cardiovascular Medicine, vol. 17, no. 7, pp. 240-246, 2007. 
[15] X. Bai, J. Ma, Z. Pan et al., "Electrophysiological properties of human adipose tissue-derived stem cells," American Journal of Physiology, vol. 293, no. 5, pp. C1539-C1550, 2007.

[16] X. L. Deng, C. P. Lau, K. Lai, K. F. Cheung, G. K. Lau, and G. R. Li, "Cell cycle-dependent expression of potassium channels and cell proliferation in rat mesenchymal stem cells from bone marrow," Cell Proliferation, vol. 40, no. 5, pp. 656-670, 2007.

[17] R. Tao, C. P. Lau, H. F. Tse, and G. R. Li, "Regulation of cell proliferation by intermediate-conductance $\mathrm{Ca}^{2+}$-activated potassium and volume-sensitive chloride channels in mouse mesenchymal stem cells," American Journal of Physiology, vol. 295, no. 5, pp. C1409-C1416, 2008.

[18] S. Zaffran and M. Frasch, "Early signals in cardiac development," Circulation Research, vol. 91, no. 6, pp. 457-469, 2002.

[19] P. P. Tam, M. Parameswaran, S. J. Kinder, and R. P. Weinberger, "The allocation of epiblast cells to the embryonic heart and other mesodermal lineages: the role of ingression and tissue movement during gastrulation," Development, vol. 124, no. 9, pp. 1631-1642, 1997.

[20] P. B. Antin, R. G. Taylor, and T. Yatskievych, "Precardiac mesoderm is specified during gastrulation in quail," Developmental Dynamics, vol. 200, no. 2, pp. 144-154, 1994.

[21] M. O. Montgomery, J. Litvin, A. Gonzalez-Sanchez, and D. Bader, "Staging of commitment and differentiation of avian cardiac myocytes," Developmental Biology, vol. 164, no. 1, pp. 63-71, 1994.

[22] Y. Han, J. E. Dennis, L. Cohen-Gould, D. M. Bader, and D. A. Fischman, "Expression of sarcomeric myosin in the presumptive myocardium of chicken embryos occurs within six hours of myocyte commitment," Developmental Dynamics, vol. 193, no. 3, pp. 257-265, 1992.

[23] T. Inagaki, V. Garcia-Martinez, and G. C. Schoenwolf, "Regulative ability of the prospective cardiogenic and vasculogenic areas of the primitive streak during avian gastrulation," Developmental Dynamics, vol. 197, no. 1, pp. 57-68, 1993.

[24] T. M. Schultheiss, S. Xydas, and A. B. Lassar, "Induction of avian cardiac myogenesis by anterior endoderm," Development, vol. 121, no. 12, pp. 4203-4214, 1995.

[25] T. A. Yatskievych, A. N. Ladd, and P. B. Antin, "Induction of cardiac myogenesis in avian pregastrula epiblast: the role of the hypoblast and activin," Development, vol. 124, no. 13, pp. 2561-2570, 1997.

[26] M. Lewandoski, "Conditional control of gene expression in the mouse," Nature Reviews Genetics, vol. 2, no. 10, pp. 743-755, 2001.

[27] M. Gossen and H. Bujard, "Studying gene function in eukaryotes by conditional gene inactivation," Annual Review of Genetics, vol. 36, pp. 153-173, 2002.

[28] A. M. Wobus, H. Holzhausen, P. Jakel, and J. Schoneich, "Characterization of a pluripotent stem cell line derived from a mouse embryo," Experimental Cell Research, vol. 152, no. 1, pp. 212-219, 1984.

[29] A. M. Wobus, G. Wallukat, and J. Hescheler, "Pluripotent mouse embryonic stem cells are able to differentiate into cardiomyocytes expressing chronotropic responses to adrenergic and cholinergic agents and $\mathrm{Ca}^{2+}$ channel blockers," Differentiation, vol. 48, no. 3, pp. 173-182, 1991.

[30] A. M. Wobus, K. Guan, H. T. Yang, and K. R. Boheler, "Embryonic stem cells as a model to study cardiac, skeletal muscle, and vascular smooth muscle cell differentiation," Methods in Molecular Biology, vol. 185, pp. 127-156, 2002.

[31] A. Kleger, T. Busch, S. Liebau et al., "The bioactive lipid sphingosylphosphorylcholine induces differentiation of mouse embryonic stem cells and human promyelocytic leukaemia cells," Cellular Signalling, vol. 19, no. 2, pp. 367-377, 2007.

[32] S. Liebau, B. Vaida, A. Storch, and T. M. Boeckers, "Maturation of synaptic contacts in differentiating neural stem cells," Stem Cells, vol. 25, no. 7, pp. 1720-1729, 2007.

[33] S. Liebau, C. Proepper, T. Schmidt, M. Schoen, J. Bockmann, and T. M. Boeckers, "ProSAPiP2, a novel postsynaptic density protein that interacts with ProSAP2/Shank3," Biochemical and Biophysical Research Communications, vol. 385, no. 3, pp. 460465, 2009.

[34] S. Liebau, C. Pröpper, T. Böckers et al., "Selective blockage of $\mathrm{K}_{v} 1.3$ and $\mathrm{K}_{v} 3.1$ channels increases neural progenitor cell proliferation," Journal of Neurochemistry, vol. 99, no. 2, pp. 426-437, 2006.

[35] K. Nehrke, C. C. Quinn, and T. Begenisich, "Molecular identification of $\mathrm{Ca}^{2+}$-activated $\mathrm{K}^{+}$channels in parotid acinar cells," American Journal of Physiology, vol. 284, no. 2, pp. C535-C546, 2003.

[36] C. E. Gustafson, S. Levine, T. Katsura et al., "Vasopressin regulated trafficking of a green fluorescent protein-aquaporin 2 chimera in LLC-PK1 cells," Histochemistry and Cell Biology, vol. 110, no. 4, pp. 377-386, 1998.

[37] D. Bosnakovski, Z. Xu, E. J. Gang et al., "An isogenetic myoblast expression screen identifies DUX4-mediated FSHDassociated molecular pathologies," EMBO Journal, vol. 27, no. 20, pp. 2766-2779, 2008.

[38] A. Holtzinger, G. E. Rosenfeld, and T. Evans, "Gata4 directs development of cardiac-inducing endoderm from ES cells," Developmental Biology, vol. 337, no. 1, pp. 63-73, 2010.

[39] A. Bondue, S. Tännler, G. Chiapparo et al., "Defining the earliest step of cardiovascular progenitor specification during embryonic stem cell differentiation," Journal of Cell Biology, vol. 192, no. 5, pp. 751-765, 2011.

[40] M. Iacovino, C. Hernandez, Z. Xu, G. Bajwa, M. Prather, and M. Kyba, "A conserved role for hox paralog group 4 in regulation of hematopoietic progenitors," Stem Cells and Development, vol. 18, no. 5, pp. 783-791, 2009.

[41] M. G. Perino, S. Yamanaka, J. Li, A. M. Wobus, and K. R. Boheler, "Cardiomyogenic stem and progenitor cell plasticity and the dissection of cardiopoiesis," Journal of Molecular and Cellular Cardiology, vol. 45, no. 4, pp. 475-494, 2008.

[42] Y. H. Ching, T. K. Ghosh, S. J. Cross et al., "Mutation in myosin heavy chain 6 causes atrial septal defect," Nature Genetics, vol. 37, no. 4, pp. 423-428, 2005.

[43] P. Pedarzani, J. Mosbacher, A. Rivard et al., "Control of electrical activity in central neurons by modulating the gating of small conductance $\mathrm{Ca}^{2+}$-activated $\mathrm{K}^{+}$channels," Journal of Biological Chemistry, vol. 276, no. 13, pp. 9762-9769, 2001.

[44] C. Hougaard, B. L. Eriksen, S. Jørgensen et al., "Selective positive modulation of the SK3 and SK2 subtypes of small conductance $\mathrm{Ca}^{2+}$-activated $\mathrm{K}^{+}$channels," British Journal of Pharmacology, vol. 151, no. 5, pp. 655-665, 2007.

[45] A. S. Monaghan, D. C. Benton, P. K. Bahia et al., "The SK3 subunit of small conductance $\mathrm{Ca}^{2+}$-activated $\mathrm{K}^{+}$channels interacts with both SK1 and SK2 subunits in a heterologous expression system," Journal of Biological Chemistry, vol. 279, no. 2, pp. 1003-1009, 2004.

[46] D. Tuteja, S. Rafizadeh, V. Timofeyev et al., "Cardiac small conductance $\mathrm{Ca}^{2+}$-activated $\mathrm{K}^{+}$channel subunits form heteromultimers via the coiled-coil domains in the $\mathrm{C}$ termini of the channels," Circulation Research, vol. 107, no. 7, pp. 851-859, 2010.

[47] T. Strassmaier, C. T. Bond, C. A. Sailer, H. G. Knaus, J. Maylie, and J. P. Adelman, "A novel isoform of SK2 assembles 
with other SK subunits in mouse brain," Journal of Biological Chemistry, vol. 280, no. 22, pp. 21231-21236, 2005.

[48] B. E. Shmukler, C. T. Bond, S. Wilhelm et al., "Structure and complex transcription pattern of the mouse SK1 KCachannel gene, KCNN1," Biochimica et Biophysica Acta, vol. 1518, no. 1-2, pp. 36-46, 2001.

[49] H. Tomita, V. G. Shakkottai, G. A. Gutman et al., "Novel truncated isoform of SK3 potassium channel is a potent dominant-negative regulator of SK currents: implications in schizophrenia," Molecular Psychiatry, vol. 8, no. 5, pp. 524535, 2003.

[50] C. Barmeyer, C. Rahner, Y. Yang, F. J. Sigworth, H. J. Binder, and V. M. Rajendran, "Cloning and identification of tissuespecific expression of KCNN4 splice variants in rat colon," American Journal of Physiology, vol. 299, no. 2, pp. C251-C263, 2010. 

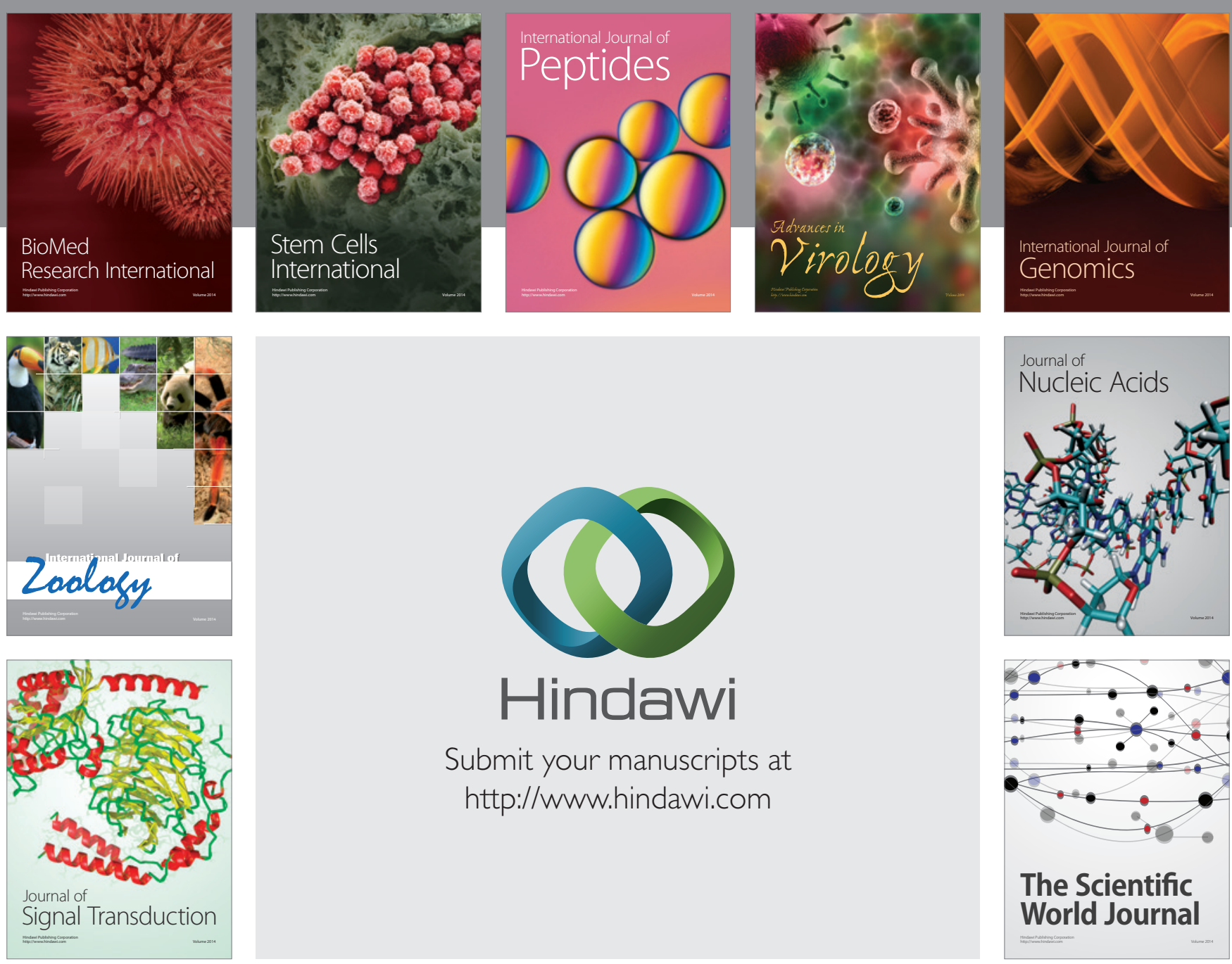

Submit your manuscripts at

http://www.hindawi.com
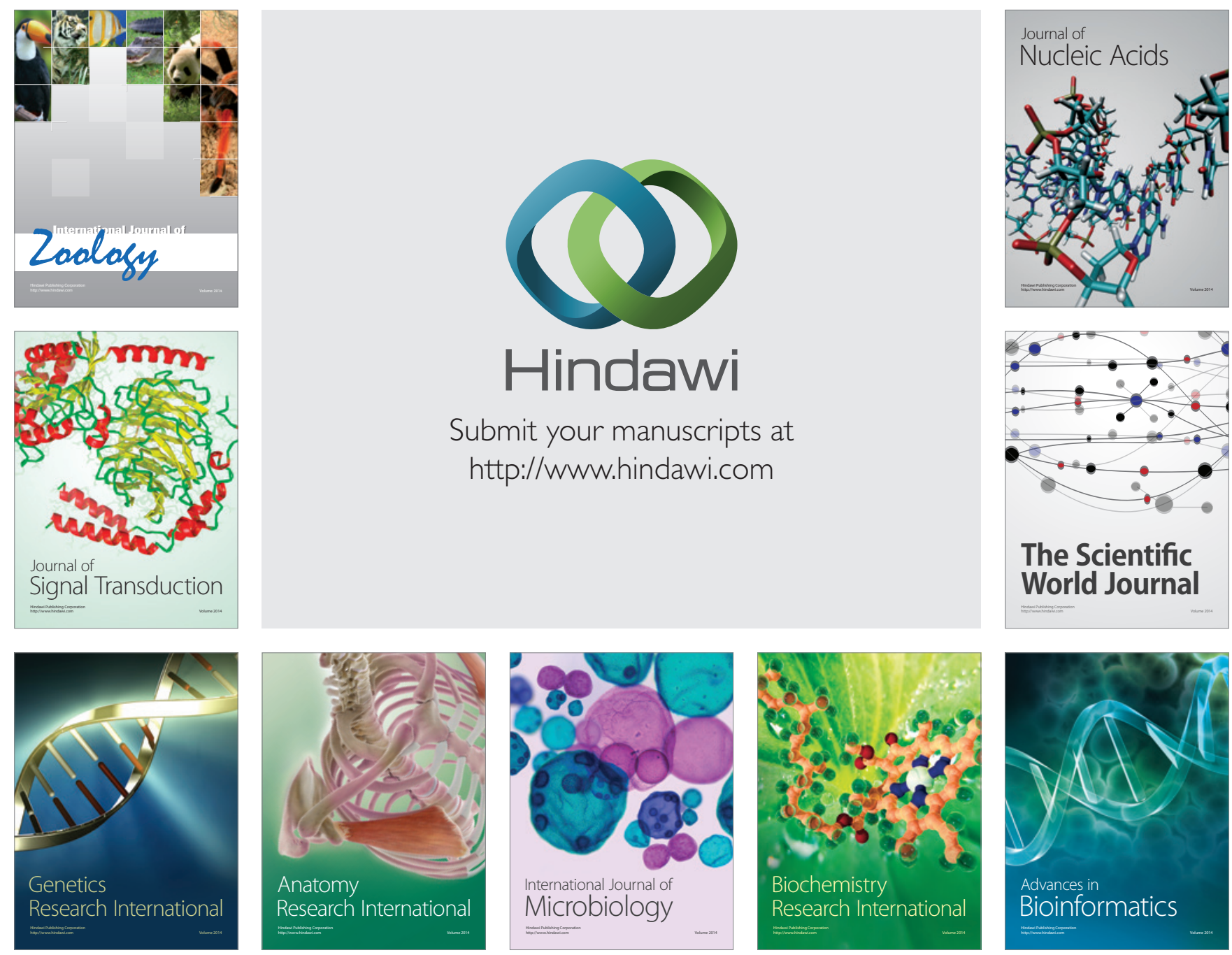

The Scientific World Journal
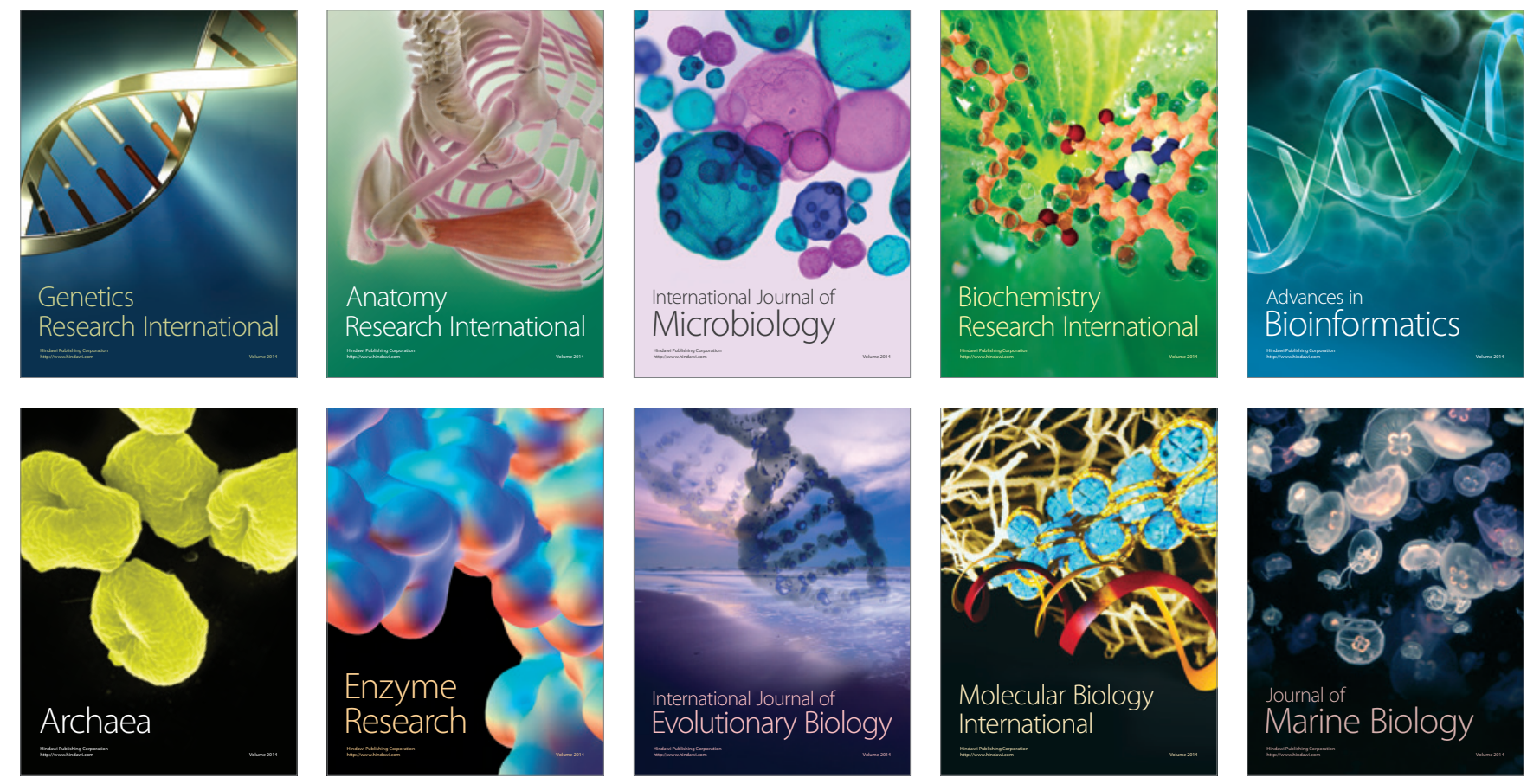